\title{
LITERALIDADE COMO METÁFORA E EQUIDADE COMO MILAGRE: UM OLHAR SOBRE A OPOSIÇÃO ENTRE NORMATIVISMO E DECISIONISMO
}

\section{LITERALITY AS A METAPHOR AND EQUITY AS A MIRACLE: A LOOK AT THE OPPOSITION BETWEEN NORMATIVISM AND DECISIONISM}

IGOR CASTRO BELTRÃO ${ }^{1}$

TORQUATO JUNIOR CASTRO²

\begin{abstract}
RESUMO: Este artigo tem por objetivo trazer uma reflexão em torno da posição do julgador enquanto autor de um texto, a decisão jurídica. Posição esta que limita a sua liberdade de dizer, na decisão, o que quiser, diante do compromisso que deve guardar com o Estado de Direito; discorre acerca dessas implicações a partir dos lugares da legalidade e da literalidade no direito positivo derivados da normatividade kelseniana em contraste com o decisionismo schmittiano, enfatizando o elemento decisionista de toda decisão; aborda a problemática da decisão jurídica como potencialmente arbitrária e a retórica como sustentação de uma crença em torno da literalidade, mesmo diante de decisões que podem ser interpretadas como contra legem, utilizando o argumento da equidade como base.
\end{abstract}

Palavras-Chave: Decisão jurídica; Decisionismo; Argumento de equidade.

ABSTRACT: This article aims to bring a reflection on the position of the judge as author of a text, the legal decision. This position limits his freedom to say, in the decision, what he wants, before the commitment that must keep with the Rule of Law; discusses these implications from the places of legality and literality in positive law derived from Kelsenian normativity in contrast to Schmittian decisionism,

\footnotetext{
${ }^{1}$ Mestrando em direito pela UFPE, Advogado. Contato: beltraodecastro@yahoo.com.br.

2 Doutor em Filosofia do Direito e do Estado pela Pontifícia Universidade Católica de São Paulo (2003). Atualmente é Professor Titular da Universidade Federal de Pernambuco, lecionando Direito Civil, Lógica, e Retórica Jurídicas. Contato: torquatojr@yahoo.com.
} 
IGOR CASTRO BELTRÃO

TORQUATO JUNIOR CASTRO

emphasizing the decision-making element of every decision; approaches the problem of legal decision as potentially arbitrary and rhetoric as the support of a belief about literality, even in the face of decisions that can be interpreted as contra legem, using the equity argument as the basis.

KEYWORDS: Legal decision; Decisionism; Equity argument.

\section{INTRODUÇÃO: A POSIÇÃO DO JUIZ NO DOMÍNIO DOS SENTIDOS E AS SINTAXES DO PONTO DE REFERÊNCIA NORMATIVO}

O juiz, como o poeta e o filósofo, é um habitante do mundo das palavras. Como seus companheiros de cidade, ele precisa aprender a lidar com a profusão de significados que nascem dessa convivência com seus companheiros no processo de comunicação (RODRIGUEZ, 2002, p. 277). Mas seu papel no domínio dos sentidos, apesar de guardar semelhanças, não se confunde com o dos outros dois.

O poeta pode ocupar o papel de criador de sentidos novos sem que isso afete diretamente o funcionamento das outras esferas sociais. Por sua vez, "pensar filosoficamente significa pensar sem compromisso com a realização de objetivos práticos" (RODRIGUEZ, 2002, p. 279). O juiz ocupa já um lugar sui generis neste cenário. Sua atividade de criador de sentidos (ou de atualizador do sentido dos textos) não pode ser livre. Nos dizeres de José Rodrigo Rodriguez, "sua função é conter a profusão de significados para conformar o sentido dos textos jurídicos aos esquadros do Estado de Direito" (RODRIGUEZ, 2002, p. 279). A esse discurso subjaz o pensamento da legalidade e "a fidelidade à lei representa um importante topos em toda cultura jurídica em que as formas de pensar inventadas na vivência com a escrita desempenham um papel decisivo na prática argumentativa" (CASTRO JR., 2009, p. 152). É preciso excluir, se possível, todo e qualquer subjetivismo na apreciação dos casos concretos que se apresentam. A função jurisdicional é vista como "espaço recortado pelas normas jurídicas, delimitado de modo estrito, que será ocupado por um sujeito que precisa livrar-se de sua singularidade para desenvolver sua atividade conforme uma rígida metodologia" (RODRIGUEZ, 2002, p. 279-280, grifos no original).

O artigo é sobre o sentido como poder organizador (ordenador) e constitutivo da vida cultural e, portanto, também do direito. É sobre a metáfora - "aquele aspecto da expressão que é menos tangível ou mensurável" (WAGNER, 2017, p. IX) - como um germe de uma disseminada tendência processual, um símbolo que evoca as relações entre a "letra" da lei, de um lado, cuja "literalidade" retoricamente faz-se passar por 
objeto empiricamente verificável (as palavras da lei sendo a própria lei), legitimando renovadamente a crença na segurança jurídica como uma crença na neutralidade e estabilidade de determinadas palavras escritas, e a decisão jurídica excepcional, na qual se julga haver exceção, no sentido schmittiano, do outro.

Nele, lei, legalidade, literalidade, dentre outros nomes jurídicos, serão tomados como metáforas e como lugares enunciativos, partindo da ideia de que por trás dos nomes sustenta-se uma complexa dimensão do social que abarca concepções, atitudes, interesses, lutas, rebeldia, conformismo, organização (LAZARUS, 2017), todo um conjunto de situações que o direito absorve e institucionaliza autorreferencialmente para que possa decidir sobre elas, dizendo que a luta entre as forças em presença está, quer se queira quer não, suspensa; que, em todo caso, a decisão tomada não será o resultado deste combate, mas o da intervenção de um poder que lhes será, a uns e aos outros, estranho e superior; que este poder está em posição de neutralidade entre elas e, por conseguinte, pode, ou em todo caso deveria, reconhecer, na própria causa, de que lado está a justiça. Portanto, no interior de um discurso de objetividade que não resiste, todavia, a uma reflexão mais profunda, como a traz a crítica decisionista e acerca do poder de que de fato dispõem os órgãos dotados de decidirem sobre uma suposta tradição da Corte e, por vezes, mesmo contra legem, nada obstante fazendo recorrente alusão à metáfora da literalidade. $\mathrm{O}$ argumento da equidade oferece, neste ponto, um suporte privilegiado à análise que ora se intenta.

Nesse sentido, no primeiro item, discorreremos brevemente acerca da potencial liberdade do autor para escrever o que quiser e do potencial analítico do universo simbólico que é a língua, instrumento não apenas de conhecimento, mas também de construção do mundo dos objetos, chamando a atenção do leitor para o papel ideológico da escrita e as repercussões políticas que o exercício desse papel pode implicar.

Na sequência, dirigiremos a nossa atenção para o autor de escritos jurídicos (das dogmáticas e decisões autenticadas), tratando da utopia do Estado de Direito e da metáfora da literalidade como um caminho de acesso à ideologia jurídica positivista calcada na crença de que as palavras do texto de lei podem ser interpretadas de uma maneira epistemologicamente neutra, objetiva, como se os significantes da norma ocupassem lugares predeterminados e ordenados que coubesse ao intérprete conhecer e fixar, como que pondo as palavras em ordem.

Depois, nos terceiro e quarto itens, falaremos um pouco acerca da crítica levantada pelo decisionismo de Carl Schmitt ao normativismo kelseniano, com especial relevo para o argumento schmittiano segundo o qual as teorias normativistas desconheceriam a especificidade da decisão como tal, o elemento decisionista de toda decisão, que não seria dedutível de maneira puramente 
normativa, para então tratarmos da decisão jurídica como o exercício de um poder capaz de se apropriar sub-repticiamente da "letra" da lei, fazendo passar por um "dever ser" um "eu quero", a partir de uma "manipulação" retórica da literalidade.

Por fim, utilizaremos o milagre como metáfora ilustrativa da maneira como, através do argumento da equidade, o julgador é capaz de sair da "letra" para alcançar um suposto "espírito" da lei, mesmo quando julga contra legem, desobedecendo-a, portanto, mantendo, contudo, a crença de que a regra não foi irrompida, e que seu "espírito" é ao final confirmado pela desobediência à "letra" do texto.

\title{
II. A INVENÇÃO DA ORDEM POR MEIO DAS PALAVRAS "EM ORDEM"
}

Walter Benjamin, em conferência pronunciada no Instituto Internacional para o Estudo do Fascismo (Internationales Institut zum Studium des Faschismus - INFA), em 27 de abril de 1934, intitulada $O$ autor como produtor, refletindo em um momento inicial de sua explanação acerca da autonomia do autor, relembrou o tratamento reservado por Platão aos poetas em sua República. No interesse da comunidade, ele (Platão) os exclui do Estado. Nas palavras do filósofo e sociólogo alemão:

\begin{abstract}
Platão tinha um alto conceito do poder da poesia. Porém julgava-a prejudicial, supérflua numa comunidade perfeita, bem entendido. Desde então, a questão do direito à existência do poeta raramente tem sido colocada com essa ênfase; mas ela se coloca hoje. Não se coloca, em geral, nessa forma. Mas a questão vos é mais ou menos familiar sob a forma da autonomia do autor: sua liberdade de escrever o que quiser (BENJAMIN, 1987, p. 120) (grifos no original).
\end{abstract}

Na ocasião, refletia-se acerca da posição do escritor no processo produtivo e da necessidade de o autor, no cerne das mais diversas expressões artísticas, mas principalmente na escrita, para os propósitos da explanação, aliado com o proletariado, assumir um compromisso ativo na modificação do aparelho de Estado preparando e participando da ação revolucionária proletária contra o capitalismo.

Tais reflexões tomam por base a ideia de que as relações sociais são condicionadas pelas relações de produção e colocam a questão de como uma obra literária se situa dentro das relações de produção da época em vez daquela que se limita a questionar como ela se situa no tocante a essas relações (como se vincula uma obra com as relações de produção da época? É compatível com elas e, portanto, reacionária, ou visa sua transformação e, portanto, é revolucionária? Por exemplo). Essa questão pode ser analisada a partir de um viés estruturante. 
Sob outra perspectiva, ao contribuírem para “a utilização (reestruturação) de certos institutos e instituições" (BENJAMIN, 1987, p. 127), a obra literária de um Tretiakov, de um Brecht, a fotografia de um Heartfield, a composição de um Eisler, dentre muitos outros elementos, podem, tomando-se um sentido inverso, servir como objeto de análise de estrutura, e isso por conta de sua natureza simbólica.

A tradição neo-kantiana trata os diferentes universos simbólicos, mito, língua, arte, ciência, como instrumentos de conhecimento e de construção do mundo dos objetos, como formas simbólicas, reconhecendo o aspecto ativo do conhecimento (BOURDIEU, 1989, p. 8).

Nesse sentido, uma análise estrutural constitui, segundo Bourdieu, um instrumento metodológico que permite realizar a ambição neo-kantiana de apreender a lógica específica de cada uma das formas simbólicas, procedendo a uma leitura propriamente tautegórica (por oposição à alegórica) que não refere o mito a algo diferente dele mesmo, "a análise estrutural tem em vista isolar a estrutura imanente a cada produção simbólica” (BOURDIEU, 1989, p. 9). Para o autor, no rastro da representação da língua para Saussure, fundador da tradição estruturalista, os sistemas simbólicos, como instrumentos de conhecimento e de comunicação, só podem exercer um poder estruturante porque são estruturados em sentidos.

Para Roy Wagner, em Saussure, o "signo" é um mediador sensorial entre conceito e percepto (assim como em outras ideias similares, como o fonema ou o tom musical) (WAGNER, 2017, p. 24), mas não apenas. Essa noção saussuriana de signo é ela mesma um "signo" desse enquadramento de suposições, "o qual centra as áreas mais essenciais do sentido em pontos de referência simbólicos, suas gramáticas e sintaxes, e assim por diante" (WAGNER, 2017, p.24), com potencial analítico.

Esse potencial analítico é, em parte, cumprido a partir da construção desse microcosmo exploratório chamado "estrutura", não importando se tomamos já os símbolos como código ou como analogia, muito embora o tratamento em termos de relação entre símbolo e a coisa simbolizada nos permita, para além de tratar do simbolismo como uma mera questão de referência, enxergar que o microcosmo de nomes $^{3}$ não é mais um microcosmo; ele estará imerso em um macrocosmo de construções analógicas. "Não temos apenas uma analogia que engloba nome e nomeado, mas uma analogia que sugere e tende a nos inserir em relações analógicas entre construtos macrocósmicos" (WAGNER, 2017, p. 21).

A identificação do signo como mediador entre percepto e conceito simbólico estabelece uma abstração - "o nascimento da ordem como fato consumado"

\footnotetext{
${ }^{3}$ Seguimos em linha com o pensamento de Sylvain Lazarus em seu Antropologia do nome segundo o qual os nomes são lugares e representam, em última análise, a vontade de captar a singularidade sem fazê-la desaparecer. O nome é, no fundo, inominável (LAZARUS, 2017, p. 7).
} 
IGOR CASTRO BELTRÃO

TORQUATO JUNIOR CASTRO

(WAGNER, 2017, p. 25) - como ato constitutivo único na emergência do sentido. Em Wagner:

Há muito se especula sobre a origem da linguagem, a invenção da abstração, que formou a Palavra no Início. Mas a realização de que o sentido é percepção, que ele ocorre no fundo "natural" a partir do qual a abstração supostamente libertou a palavra, nos leva a pensar que a "abstração" é, ao contrário, parte de um processo contínuo e generativo. A invenção de um microcosmo a partir de um macrocosmo perceptual, a partir da abstração, é metade de uma interação dialética altamente carregada, estabelecendo um contínuo sensorial no qual o ordenamento e a reconfiguração do sentido são consumados. A outra metade dessa interação carregada é uma expansão, ou concretização, igualmente importante, do microcosmo em macrocosmo, que ocorre na formação da analogia. A invenção do microcosmo, do símbolo e da linguagem, e do macrocosmo, o sentido e o mundo significativo, são aspectos relacionados, dialética e intrinsecamente, de um mesmo processo (WAGNER, 2017, p. 25-26) (grifos no original).

$\mathrm{O}$ autor de $A$ invenção da cultura, contudo, alerta para o fato de que "o sentido requer um absoluto forjado, como uma espécie de 'mentira' epistemológica, para enquadrar tais verdades na forma como é capaz de exprimi-las"' (WAGNER, 2017, p. 32). Pela mesma razão, o antropólogo afirma que a percepção não é, de maneira alguma, equivalente às produções estéticas por meio das quais a expansão do alcance sensorial se realiza, ainda que esteja ligada a e seja instruída por elas.

A linguagem é, essencialmente, simbólica. Mas, nesses lindes, a metáfora ocupa um ponto privilegiado de análise do que queremos demonstrar. E, aqui, é-nos mais interessante não propriamente o que a metáfora "faz", mas, mais importante, o que se pode fazer com a metáfora.

Uma metáfora, no texto de Roy Wagner, equaciona um ponto de referência convencional, ou substitui um pelo outro, e obriga o intérprete a tirar suas conclusões de acordo. "Ela elicia analogias, como percepções através da linguagem, por assim dizer, e essas analogias ou percepções tornam-se a intenção e o conteúdo da expressão" (WAGNER, 2017, p. 8) (grifos no original).

O uso figurativo, portanto, uma vez que faz da referência convencional uma espécie de prisma, não pode oferecer um campo de referência literal. Ele não é formado por meio da "indicação" das coisas, ou referenciando-as, mas "relacionando ponteiros ou pontos de referência uns com os outros, colocando-os em uma relação 
inovadora no tocante à ordem de referência inicial" (WAGNER, 2017, p. 8). Ele, portanto, "expressa" uma relação renegociada, mas, não sendo "literal" em nenhum aspecto, não pode "apontá-la". Assim, podemos dizer, com Wagner, que ele "incorpora" ou "reflete" seu objeto, configurando-o simpateticamente ao transformar a si mesmo naquilo que é expresso. É um símbolo que representa a si mesmo.

\begin{abstract}
Quando falamos em coisas que não possuem referentes convencionais, nossa forma de falar deve tornar-se ela mesma o referente. $\mathrm{O}$ efeito da construção é incorporado ao incidir sobre o ponto de referência tradicional; essa incidência é, ao mesmo tempo, o que ela é e sobre o que ela é. Um símbolo autista, um símbolo que representa a si mesmo, não é tanto uma impossibilidade quanto uma inanidade - quem se importa? Tal construto se torna interessante e relevante para alguém apenas na medida em que aborda - converte, inverte, reverte, subverte, perverte - e se relaciona com pontos de referência tradicionais (WAGNER, 2017, p. 8-9) (grifos no original).
\end{abstract}

Nesse sentido, a liberdade que era aconselhado negar aos poetas, na República platônica parece estar relacionada à capacidade de esses poetas, com suas fábulas, moldarem as almas, os pensamentos dos indivíduos, em torno de apreensões falsas, mal delineadas, subversivas - e que, portanto, mereciam ser censuradas -, da maneira de ser dos deuses e heróis que se assumia não apenas como verdadeira, mas também como desejável para a cidade. Os seus autores deveriam ser vigiados e aos formadores da cidade cabia-lhes o dever de escolher as fábulas boas e proscrever as más (PLATÃO, 2008, p. 65-66).

\title{
III. O COMPROMISSO DO JURISTA DE COLOCAR AS PALAVRAS EM SEUS “DEVIDOS” LUGARES
}

Para Luis Alberto Warat, o Estado cumpre um papel de "polícia das perfeições" 4 , e cabe à legalidade atenuá-lo (WARAT, 1994, p. 25), o que ela faz através de uma utopia, qual seja, o sistema de representações expressado pela ideia de Estado de Direito.

A operacionalização da concepção jurisdicista, das crenças que sustentam a ideologia do Estado de Direito, em suas lições, se dão por meio da dissolução de

\footnotetext{
${ }^{4} \mathrm{Na}$ simulação de um Estado absolutamente controlado pela lei, graças à previsão da existência de uma razão com suficiente força para garantir o caráter ético do Estado (WARAT, 1994, p. 24-25).
} 
IGOR CASTRO BELTRÃO

TORQUATO JUNIOR CASTRO

todas as dimensões do poder do Estado na lei, "mostrando as práticas do Direito como um dique de contenção do arbítrio, proclamando a lei como um instrumento da razão que preserva tanto a liberdade como a igualdade" (WARAT, 1994, p. 20-21).

Constroem-se, assim, saberes externos à sociedade, negando todas as suas insuficiências e perdas, mostrando-as realizadas pelas palavras. "O discurso jurídico inverte os despojos e as exclusões sociais apresentando-os como direitos do homem" (WARAT, 1994, p. 21).

Esse sistema de representações, na opinião do professor argentino, apesar de uma utopia perfeita, torna-se ineficiente na medida em que fecha as práticas feitas em seu nome a todo desenvolvimento produtivo dos antagonismos sociais. Dessa forma, fracassa como expressão jurídica da democracia negando-se a reconhecer que os sentidos da lei não existem como formas perfeitas de uma escrita e nem como momento dialético de campos de luta.

Segundo ele, é pouco plausível o uso do direito como formador do sentido democrático de uma sociedade, se ele não admite o valor positivo do conflito, "se escamoteia, em nome de uma igualdade formal e perfeita, as desigualdades econômicas e culturais, se esquece que a lei é sempre a expressão de interesses e de práticas de poder" (WARAT, 1994, p. 22).

Ainda, por estarem perdidas em um sentimento "oceânico" freudiano, explicado como a "presunção de atingir uma relação com o mundo, sentido como um vínculo com a totalidade, experimentado como algo já dado e não como algo a conquistar" (WARAT, 1994, p. 24), as utopias cumprem o papel de um "objeto evocativo" que fascina e impede a reflexão, inibindo, portanto, a ação.

A aplicação da lei fica garantida por um "clima" de sentidos que afirmam, no discurso, as práticas do Direito que muitas vezes negam à sociedade. Como no discurso amoroso, os juristas falam do que não têm, para sustentar muitos "desejos" (reivindicações de novos direitos) em sua perda: trata-se de uma representação implementada para dissolver, numa miragem simbólica, carências insustentáveis, faltas que precisam ser faladas para que se possa imaginá-las preenchidas (WARAT, 1994, p. 21).

Concretamente, a discursividade do direito, caracterizada como "magnética" por Luis Alberto Warat, serve, sem muitos inconvenientes, para a estabilização e consolidação de sentidos que perturbam as possibilidades de uma forma democrática. "O discurso jurídico, em suas múltiplas manifestações, tem aversão a tudo quanto é novo" (WARAT, 1994, p. 25). 
Segundo Bourdieu, o debate científico a respeito do direito é dominado pelas alternativas do formalismo, que afirma a autonomia absoluta da forma jurídica em relação ao mundo social, e do instrumentalismo, que concebe o direito como um reflexo ou um utensílio ao serviço dos dominantes. Em suas palavras:

A ciência jurídica, tal como a concebem os juristas e, sobretudo, os historiadores do direito, que identificam a história do direito com a história do desenvolvimento interno dos seus conceitos e dos seus métodos, apreende o direito como um sistema fechado e autônomo, cujo desenvolvimento só pode ser compreendido segundo a sua dinâmica interna (BOURDIEU, 1989, p. 209).

Dentro do positivismo do século XIX, ainda ligado ao empirismo e ao trato com o concreto, lembra-nos Nelson Saldanha, lavrava a sutil tendência ao formalismo. O autor menciona a sua presença nos publicistas alemães da linha de Laband, de Gerber e Seydel, que, segundo ele, buscavam evitar não apenas (e basicamente) toda metafísica, mas também toda conotação social e "política" (SALDANHA, 2005, p. 67). $\mathrm{O}$ acento com que se recusava de plano todo jusnaturalismo, segue a sua análise, em nome de um direito evidentemente positivo, abria um claro no lugar do antigo e fundante jus naturale, e este claro era como uma forma, que tinha de preencher-se (SALDANHA, 2005, p. 67). A possibilidade de um tratamento científico do direito veio com o cancelamento da ideia de um fundamento que o preenchesse da espécie dos que vieram nos tempos da teologia e do racionalismo metafísico, passando a importar apenas a própria forma, "antes função de um fundamento e agora coisa autônoma, ponto de referência para a própria possibilidade de um tratamento 'científico' de determinado objeto" (SALDANHA, 2005, p. 67).

A reivindicação de autonomia absoluta do pensamento e da ação jurídicos afirmase na constituição em teoria de um modo de pensamento específico, totalmente liberto do peso social, e a tentativa de Kelsen para criar uma teoria pura do direito "não passa do limite ultra-consequente do esforço de todo o corpo dos juristas para construir um corpo de doutrinas e de regras completamente independentes dos constrangimentos e das pressões sociais, tendo ele mesmo o seu próprio fundamento" (BOURDIEU, 1989, p. 209).

A contribuição essencial do positivismo, salvo a sistematização das técnicas de explicitação e interpretação dos textos jurídicos, para Kervégan, é ter dado crédito à equivalência entre direito e lei positiva (KERVÉGAN, 2006, p. 3-4). Compreendida a partir de seu papel histórico e político, tal identificação se insere, relata, no combate travado no século XIX pela burguesia liberal contra as estruturas políticas 
IGOR CASTRO BELTRÃO

TORQUATO JUNIOR CASTRO

autoritárias do "Estado governamental" monarquista. O positivismo, no domínio do direito público, não pode senão legitimar a nova fórmula política do "Estado de direito" (Rechtsstaat) que, em sua essência, é um Estado legislador (Gesetzgebungstaat). Nessas condições, a doutrina positivista, que faz da vontade legalmente expressa do legislador legalmente competente a única fonte do direito, acompanha a instalação de um regime parlamentar, fazendo da legalidade "a forma exclusiva da legitimidade política e, mais amplamente, do direito como tal: com ela, e sem dúvida pela primeira vez, 'o pensamento do direito se torna pensamento da legalidade'” (KERVÉGAN, 2006, p. 4).

Segundo Saldanha, a preocupação kelseniana em tratar o jurídico apenas "como jurídico" (e o entendimento disto como "formalismo" e juspositivismo) poderia ser situada em relação a uma série de expressivas formulações da história das ciências sociais. $\mathrm{O}$ autor se refere a formulações, a um tempo metodológicas e doutrinárias, ocorridas em cada grande área por conta de especiais "momentos" históricos. Por exemplo, a explicação do político pelo político devida a Rousseau; a explicação do social pelo social por mãos de Durkheim; e talvez, de certo modo, a explicação da história pela história na obra de Spengler (SALDANHA, 1987, p. 62-63). São formulações que contrastam com as explicações vinculatórias, que entendem o histórico em função do econômico, ou o político em função do ético. "Em Kelsen, a análise do jurídico como tal teve de resolver-se pela construção de um sistema essencialmente formal, constituído de normas e de competências" (SALDANHA, 1987, p. 63) (grifos no original). Na ordem das definições, a preocupação central é a de construir uma ciência em sentido estrito para o direito, apelando a um sistema de conceitos fundantes, que permitem a delimitação precisa do campo jurídico, estipulativamente". "As teses kelsenianas sobre as definições jurídicas, aparentemente plausíveis, apenas podem ser aceitas após a concordância com os pressupostos epistemológicos do Neopositivismo e com os papéis que eles reservam às definições na ciência" (WARAT, 1984, p. 59). A inspiração é Kant.

A posição normativista, isto é, a consideração do direito como sistema de normas, tem sido sempre contraposta ao decisionismo e isto, de acordo com Nelson Saldanha, desde que Carl Schmitt situou a distinção entre os três tipos essenciais de

\footnotetext{
${ }_{5}^{5}$ Pode-se falar em estipulação em diversos sentidos. Por vezes, ela consiste na escolha contextual de um termo ambíguo. Assim, por exemplo, e o exemplo é de Warat (1984, p. 57), a expressão "democracia" tem um sentido denotativo incerto, dependente de critérios axiológicos. Desta forma, quando o indivíduo explicita a designação que dá ao termo, estará elaborando uma definição estipulativa. Este tipo de estipulação ocorre como opção entre várias definições lexicográficas. Em outros casos, podemos falar de estipulação para as situações em que se introduz um termo novo ou se propõe um sentido diferente para um termo de uma linguagem já em uso. Esta última a perspectiva kelseniana.
}

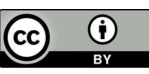

5 JOURNAL OF INSTITUTIONAL STUDIES 2 (2019)

Revista Estudos Institucionais, v. 5, n. 2, p. 615-638, maio/dez. 2019 
pensamento jurídico contemporâneo - o normativismo, o decisionismo e o pensamento do direito como ordem concreta (SALDANHA, 1987, p. 65).

O chamado decisionismo era "um prolongamento do autoritarismo de Hobbes: a ele corresponde a visão do direito como obra de uma vontade, configurada em sua potência comendadora independentemente da razão e da 'verdade'" (SALDANHA, 1987, p. 65). O pensamento "ordenamental-concreto" (esta sim a posição de Schmitt, segundo Saldanha) situa o jurídico num encaixe de condições existenciais, dentro, aliás, de uma tradição romântica. O normativismo, historicamente vinculado à ideia liberal de um governo "de leis, não de homens", vê no direito um conjunto de normas, entendidas em sua pura e racional objetividade.

Uma imagética de reflexividade e objetividade da linguagem cuja base é preparada pelos conceitos de "legalidade" (fidelidade à lei) e "literalidade" (fidelidade ao texto), cujas correlações são evidentes no nascedouro, pois que a "lei" era o que se lia; e o que se lia era a letra (da lei), tem importante valor persuasivo no que toca à perpetuação de certas crenças teóricas dos juristas.

A univocidade implícita na ideia de que há um sentido literal, ou mesmo alguns, em cada palavra ou frase aponta para a identificação de suas "condições de verdade", que a concepção metafórica da "teoria" enquanto "visão" faz crer ser um "decalque" do mundo. Os usos não literais, como a metáfora, a sinédoque, a ironia, seriam aspectos secundários e imperfeitos, derivados já de um jogo que se realiza desde a original correspondência "na letra" entre um signo e seu significado.

No direito, como na lógica, mas aqui já por imposições pragmáticas relativas à legitimidade da decisão dos conflitos segundo a legislação, também se assume um "princípio da univocidade" para os textos-fonte. Na expressão clássica, "a letra da lei", com que o jurista se refere frequentemente ao sentido "literal" de um texto legal, "letra" se mostra como metáfora significando a reflexividade entre a palavra, i.e. o signo, e o seu significado. "Todo o esforço para produzir e interpretar as fontes textuais, do modo tradicional como é concebido, consiste em encontrar um caminho para determinar a esclarecer o sentido que já está na "letra da lei" e que é supostamente unívoco" (CASTRO JR., 2009, p. 154).

As objeções epistêmicas a essa pretensão que, por exemplo, Kelsen (1984, p. 465) apresenta parecem, porém, irrefutáveis. Não poder demonstrar aprioristicamente o sentido literal de um texto, todavia, não impede de usar a noção de "sentido literal" mesma para estruturar uma imagem, ainda que metafórica, do direito.

Perceba-se que, conforme antecipamos, o conceito de signo é necessariamente relacional, seja quando se o concebe segundo um modelo binário, como em Saussure, ou como um modelo terniário, como em Pierce. O signo é "algo que está no lugar de algo". A metáfora espacial "no lugar de..." faz pressupor que há alguma "situação", 
alguma "ordem" na qual se pode verificar onde se situam as coisas. "Estar no lugar de" faz pressupor que, em relação a essa ordem, algo se situa "fora" de seu próprio lugar. O signo, então, é uma coisa, em certo sentido, "fora do seu lugar". Em outras palavras, estar "fora de lugar" significa que o signo, que também tem sempre algo de físico, como uma marca no papel que muitas vezes é, eis que não está sendo tomado desde esse seu lugar físico como uma marca no papel. Essa sua outra situação nãofísica não se compreende apenas extensionalmente. É intencional. Assim, o signo, que está "fora de lugar", está em alguma medida fora do espaço físico. Por isso também, toda a teoria do signo, mesmo quando feita a partir de premissas estritamente comportamentais e pragmáticas, como as de Peirce e Morris, "não alcança ser ciência 'em sentido literal'; não cuida do que se possa pesar e medir. Em relação à ciência, a semiótica, como a pragmática, serão apenas metáforas 'bem comportadas'" (CASTRO JR., 2009, p. 155).

É interessante observar que a metáfora "estar no lugar de..." introduz, por um lado, a tensão de uma norma, mas, por outro, também já seu descumprimento. $\mathrm{O}$ "lugar natural das coisas", pode estar pressuposto, desde uma visão estrita da ciência em sentido literal, será seu lugar físico, ou o da sua experiência sensorial. Porém o signo define-se ainda pelo fato de que foge a essa regra. "O lugar de", por outro lado, faz pressupor a existência de uma relação exclusiva, já que se tem também por pressuposto que não se pode estar em dois lugares ao mesmo tempo. Assim, configura-se a implicitação ainda que relativa de que cada lugar ocupado por um signo é de uma e apenas uma coisa. Isso possivelmente favorece a suposição de que ordinariamente a um signo corresponde um significado, ao menos em caráter principal, ordinário. Num lugar a palavra, noutro o seu significado. "Na ideia de 'literalidade', 'letra' representa uma noção em que a palavra e o significado são ligados reflexivamente, ainda que isso seja 'apenas uma métáfora'" (CASTRO JR., 2009, p. 155).

Haver um significado literal é uma pressuposição forte na doutrina do direito, de forma que as palavras, no direito, não podem estar em qualquer lugar.

\section{O ELEMENTO DECISIONISTA}

Voltando à questão da contraposição normativismo e decisionismo, é importante elucidar, no rastro de Kervégan, que, de acordo com o próprio Schmitt, o positivismo é uma combinação, na verdade confusa e contraditória, das duas epistemologias opostas. O positivismo é tacitamente decisionista, já que reconhece como única fonte estatutária do direito a decisão soberana do legislador. Porém, ele interpreta essa decisão segundo uma perspectiva normativista; uma vez adquirida a forma legal, a decisão tem, para ele (Schmitt), a força de uma norma incondicionada: "pressupõe, 
assim, segundo os próprios termos de Jellinek, uma 'força normativa do factual'" (KERVÉGAN, 2006, p. 4). Portanto, existe no positivismo jurídico um equívoco que transcreve, aliás, a sua compreensão da positividade. O direito positivo é, antes de tudo, aquilo que o legislador quer; mas a lei promulgada se separa, por assim dizer, da decisão que a instaura como fato jurídico, e se torna uma norma autossuficiente, "positiva", pois é dotada de uma racionalidade intrínseca que a exegese científica e a jurisprudência têm precisamente como tarefa reconstruir, como que colocando as palavras em ordem.

Cumpre lembrar, com Tercio Sampaio, que o próprio dubium jurídico (conflito institucionalizado) é dotado de reflexividade, na medida em que a constituição da alternativa em relação a uma norma pode ser de novo questionada, isto é, o que se questiona, então, não são as possibilidades estruturadas em alternativas, mas a própria relação à norma que permite essa estruturação. Vale dizer, reflexivamente, o dubium jurídico acaba por se instalar dentro da própria norma (FERRAZ JR., 2015, p. 93). Isso significa que, no discurso jurídico, pela pena do autor:

Não só as normas estruturam as possibilidades alternadas, mas as próprias normas, reflexivamente, são questionadas em função de outras normas, donde a observação de Kalinovski segundo a qual as regras de substituição do "sistema linguístico" do Direito pertencem ao "sistema como tal", isto é, elas também são regras jurídicas (FERRAZ JR., 2015, p. 93).

A captação do objeto do discurso jurídico como um dubium ${ }^{6}$ que não só se refere a uma norma, mas que se instaura dentro da própria norma, em termos de reflexividade, permite-nos entender a dialogicidade própria do direito, segundo Ferraz, como dialogicidade normativa (FERRAZ JR., 2015, p. 93). Sendo a norma jurídica não um a priori formal, mas, ela própria, "o produto de um processo decisório multidimensional, sob o ponto de vista do discurso, ela é uma ação linguística racional, no sentido de discurso fundamentante" (FERRAZ JR., 2015, p. 94).

Produto de uma decisão, a norma decide, por sua vez, sobre eventuais conflitos, resultantes da recusa de comunicar-se dos "parceiros sociais". Na terminologia adotada por Tercio Sampaio, diz-se que a norma instaura uma discussão-contra ${ }^{7}$ e, concomitantemente, em termos de reflexividade, ela pressupõe também uma

${ }^{6}$ Questão conflitiva jurídica (FERRAZ JR., 2015, p. 87).

7 Entendida como aquela (reativa parte-parte) em que a função da fundamentação é configurar o conflito, possibilitando a decisão (FERRAZ JR., 2015, p. 90-91). 
IGOR CASTRO BELTRÃO

TORQUATO JUNIOR CASTRO

discussão-contra. Em ambos os casos, a própria norma permanece sempre como o centro do diálogo. Nesse sentido, o direito não é apenas um discurso sobre normas, mas é, ele próprio, normativo. Daí o caráter normativo da sua dialogicidade, no sentido de que estamos, no plano jurídico, obrigados a dialogar.

Esse positivismo, segundo Carl Schmitt, não representa, na realidade, mais que uma sobrevivência do século XIX: as condições que permitiram o seu desenvolvimento, aquelas de um Estado legislador estável, não estão mais em curso. Pelo menos ele orienta a atenção para o estatuto da norma legal, consequentemente para a relação entre norma e decisão no direito. Essa questão, de acordo com Kervégan (2006, p. 5), está no cerne da controvérsia entre Carl Schmitt e Hans Kelsen e trata inicialmente das condições de efetividade da norma jurídica e do estatuto da ciência do direito, e em seguida dos conceitos fundamentais do direito constitucional: constituição, lei, soberania.

A principal censura dirigida por Schmitt a Kelsen é que ele dissocia os dois componentes que, segundo ele, todo fato jurídico comporta: a norma e a decisão. Ao fazer da ordem jurídica um sistema fechado de normas, essa conduta inverte a prioridade, julgada absoluta por Schmitt, da decisão, ou antes, do "elemento decisionista", no próprio seio da ordem jurídica. Tal formulação visa evidentemente, segundo Kervégan, os temas diretores da teoria pura do direito: a ideia de uma ordem jurídica normativa e a ideia de norma fundamental ou de norma das normas. Fica claro, a partir daí, que existe uma oposição clara entre o conceito normativista (kelseniano) e o conceito decisionista (schmittiano) do direito; ela se traduz, especialmente, pela "rejeição, fora da teoria pura do direito, das considerações de ordem 'política' ou 'sociológica', isto é, de tudo aquilo que, para Schmitt, constitui o elemento decisionista" (KERVÉGAN, 2006, p. 6).

O que Schmitt censura, de um modo geral, nos princípios normativistas, é a sua incapacidade de criar o vínculo necessário entre a racionalidade jurídica - aquela da teoria do direito - de um lado e, de outro, segundo ele, a efetividade primária de uma decisão política. Carl Schmitt opera, em sua crítica a Kelsen, uma "subordinação do racional ao positivo e, mais precisamente, do componente normativo do direito ao seu elemento decisionista" (KERVÉGAN, 2006, p. 7). Existe, efetivamente, em todo normativismo, uma dupla deficiência e, na opinião do autor da Teologia política, a construção kelseniana revela isso.

Jean-François Kervégan assim as descreve:

O normativismo esquece, ou finge esquecer, que uma norma não saberia produzir, por si própria, as condições de sua efetuação, que a facticidade de uma ordem jurídica concreta não é dedutível da coerência formal de seu fundamento normativo. Ignorando, ou 
fingindo ignorar que "a ideia do direito não pode efetuar-se por si mesma", o normativismo contorna a questão da decisão, ou então a recusa como extrajurídica. Ora, é justamente esse elemento irredutível - o direito tem vocação para informar a efetividade social e política - que provoca a deficiência da ideia de norma, ou de sistema de normas. Tal ideia, de fato, "não diz nada a respeito daquele que deve aplicá-la": a decisão singular de um juiz nunca é redutível às suas considerações, e o conteúdo de uma lei não pode ser deduzido, enquanto tal, das disposições constitucionais. A primeira deficiência das análises de Kelsen e de qualquer outra teoria normativa é, portanto, que "elas desconhecem a especificidade da decisão como tal, o elemento 'decisionista' de toda decisão, que não é dedutível de maneira normativa". (...) A segunda deficiência do normativismo (...): é incapaz de levantar e de resolver a questão da exceção, da anormalidade, a não ser declarando-a não jurídica. Ora, desde a sua obra Die Diktatur (1921), Carl Schmitt sustenta, ao contrário, a tese de que apenas a exceção, o extremus necessitatis casus, permite ter acesso à essência do direito e revelar o seu componente decisionista. Não é que a questão política da decisão apareça somente quando o direito, ou a ordem jurídica, se cala, ou seja, quando é reduzida ao silêncio; muito pelo contrário, é quando se apresenta um caso não previsto pelo sistema de normas que se levanta em toda a sua nitidez a questão jurídica "quem decide efetivamente?", e que se revela, então, como o elemento decisionista e singular, irredutível à generalidade normativa, da ordem jurídica. É impossível, em outras palavras, definir a soberania fazendo abstração das condições nas quais ela adquire um significado concreto. Ora, essas condições, necessariamente singulares, não podem ser definidas ou prescritas, justamente porque constituem uma infração à ordem jurídica em vigor (KERVÉGAN, 2006, p. 7-8).

O filósofo francês faz ainda a ressalva de que não se trata aqui da velha questão dos limites políticos do direito: Schmitt não admite, justamente, a separação entre jurídico e político, entre normativo e efetivo. A exceção ("estado de emergência, "estado de exceção", "estado de sítio"...) não manifesta, segundo ele, os limites do direito: ela esclarece o componente decisionista, que "normalmente" está à parte. "O estado de exceção revela, em sua brutalidade, o fundamento da ordem jurídica e, por conseguinte, da norma: 'é soberano aquele que decide sobre o estado de exceção'. Em 
outras palavras: a última condição da validade normativa é o poder de afirmação dessa validade" (KERVÉGAN, 2006, p. 8).

A crítica de Kelsen e do normativismo dá acesso ao núcleo teórico original do pensamento do direito de Carl Schmitt: ela subordina a normatividade, que é a propriedade manifesta da regra de direito, às condições efetivas de sua instauração, às "decisões" fundadoras da ordem jurídica. Uma vez reconhecido o interesse jurídico associado à situação de exceção enquanto tal, convém romper com os hábitos de pensamento dominantes entre os juristas, que excluem precisamente a exceção, ou a consideram apenas violação factual da norma, não afetando em nada a sua essência.

\section{A DECISÃO JURÍDICA COMO FORMA DE APROPRIAÇÃO DA LITERALIDADE}

No texto jurídico estão em jogo lutas, pois a leitura é uma maneira de apropriação da força simbólica que nele se encontra em estado potencial (BOURDIEU, 1989, p. 213).

O campo jurídico é o lugar de concorrência pelo monopólio do direito de dizer o direito, nas palavras de Pierre Bourdieu, a boa distribuição (nomos) ou a boa ordem, na qual se defrontam agentes investidos de competências ao mesmo tempo social e técnica que consiste essencialmente na capacidade reconhecida de interpretar (de maneira mais ou menos livre ou autorizada) um corpus de textos que consagram a visão legítima, justa, do mundo social.

Ocorre que essa concorrência entre os intérpretes está limitada pelo fato de as decisões judiciais só poderem distinguir-se de atos de força políticos na medida em que se apresentem como resultado necessário de uma interpretação regulada de textos unanimemente reconhecidos. Segundo Bourdieu, como a igreja e a escola, a justiça organiza segundo uma estrita hierarquia não só as instâncias judiciais e os seus poderes, portanto, as suas decisões e as interpretações em que elas se apoiam, mas também as normas e as fontes que conferem a sua autoridade a essas decisões. É, pois, um campo que, pelo menos em período de equilíbrio, tende a funcionar como um aparelho "na medida em que a coesão dos habitus espontaneamente orquestrados dos intérpretes é aumentada pela disciplina de um corpo hierarquizado o qual põe em prática procedimentos codificados de resolução de conflitos entre os profissionais da resolução regulada dos conflitos" (BOURDIEU, 1989, p. 214). Nesse sentido, tanto fácil ao corpo de juristas convencer-se de que o direito tem seu fundamento nele próprio, quer dizer, em uma norma fundamental tal como a Constituição como norma normarum, sob o efeito de uma apriorização inscrito na lógica do funcionamento do campo jurídico para cujo processo concorrem efeitos maiores dos processos 
linguísticos característicos da linguagem jurídica, quais sejam, o efeito de neutralização (com o predomínio de construções passivas e frases impessoais) e o efeito de universalização, obtido por meio de vários processos convergentes, tais como o recurso sistemático ao indicativo para enunciar normas, o emprego, próprio da retórica da oficialidade e do auto, de "verbos atestativos na terceira pessoa do singular do presente ou do passado composto que exprimem o aspecto realizado (aceita, confessa, compromete-se, declarou, etc.)" (BOURDIEU, 1989, p. 216), o uso de indefinidos e do presente intemporal - ou do futuro jurídico - próprios para exprimirem a generalidade e a omnitemporalidade da regra do direito, etc. e que ajudam a compor o que Bourdieu define como máscara ideológica (BOURDIEU, 1989, p. 216).

Tudo isso sem que seja possível isolar uma metodologia perfeitamente racional na interpretação. A aplicação necessária de uma regra de direito a um caso particular é na realidade uma confrontação de direitos antagonistas entre os quais o tribunal deve escolher. E neste cenário, o juiz, ao invés de ser sempre um simples executante que deduzisse da lei as conclusões diretamente aplicáveis ao caso particular, dispõe antes de uma parte de autonomia, vamos dizer aqui, soberania, que constitui "a melhor medida da sua posição na estrutura da distribuição do capital específico de autoridade jurídica" (BOURDIEU, 1989, p. 222). Os seus juízos, que se inspiram numa lógica e em valores muito próximos dos que estão nos textos submetidos à sua interpretação, têm uma verdadeira função de invenção. Se a existência de regras escritas tende a reduzir a variabilidade comportamental, nas lições de Bourdieu, não há dúvida também de que a conduta dos agentes jurídicos podem referir-se e sujeitar-se mais ou menos estritamente às exigências da lei, ficando sempre uma parte de arbitrário, imputável a variáveis organizacionais como a composição do grupo de decisão ou os atributos dos que estão sujeitos a uma jurisdição, nas decisões judiciais. Para o autor, a interpretação opera a historicização da norma:

adaptando as fontes a circunstâncias novas, descobrindo nelas possibilidades inéditas, deixando de lado o que está ultrapassado ou o que é caduco. Dada a extraordinária elasticidade dos textos, que vão por vezes até a indeterminação ou ao equívoco, a operação hermenêutica de declarativo dispõe de uma imensa liberdade. Não é raro, decerto, que o direito, instrumento dócil, adaptável, flexível, polimorfo, seja de facto chamado a contribuir para racionalizar ex post decisões em que não teve qualquer participação (BOURDIEU, 1989, p. 223-224). 
IGOR CASTRO BELTRÃO

TORQUATO JUNIOR CASTRO

Podemos dizer, enfim, coisa que os realistas já reconhecem há bastante tempo: a interpretação contra legem não existe, porquanto o efeito da interpretação autêntica é que ela se impõe qualquer que seja o seu conteúdo. $\mathrm{O}$ texto interpretado não tem e não pode ter outro significado além daquele que lhe é dado pela autoridade competente (TROPER, 2001, p. 71-72) ${ }^{8}$, traduzindo-se a interpretação em uma forma de poder. E sequer o texto poderia ser oponível ao intérprete, uma vez não é direito antes de realizada a interpretação (PICARD, 2009 apud JUST; ASSIS, 2014, p. 168).

\section{EQUIDADE COMO MILAGRE}

Mas falávamos de Schmitt. A decisão de um caso de exceção é uma questão central na teoria política e jurídica de Carl Schmitt. Para ele, como é sabido, o soberano é quem pode decidir em caso de exceção (SCHMITT, 2006, p. 7), isto é, quem pode dizer quando há uma exceção e como ela deve ser tratada (SCHMITT, 2006, p. 8).

A especial nota distintiva do caso excepcional, é a de não ser ele previamente descrito na ordem jurídica vigente. Em outras palavras, não ser descrito como um pressuposto legal. Os pressupostos são, aqui, assim como o conteúdo da competência, necessariamente, ilimitados (SCHMITT, 2006, p. 8), especialmente porque a necessidade de decidir ante os casos excepcionais não pode contar nem com a participação do povo, que só se projeta como tal quando está em condições de aclamar, nem com a decisão fundamental plasmada na Constituição. A norma necessita de um meio homogêneo, de uma normalidade fática (SCHMITT, 2006, p. 13). Neste último caso, a ordem constitucional representa justamente a normalidade que precisa e fatalmente vai ser quebrada pela urgência que envolve o caso excepcional.

A compreensão de Schmitt sobre esses fatos sociais tem uma base sociológica, na qual o cerne é atribuído à "sociologia compreensiva" de Max Weber. Portanto, Schmitt é fundamentalmente consciente da atividade criadora de significados dos seres humanos na sociedade. Em sua concepção da teoria do Estado como "teologia política", ele afirma que a imagem metafísica do mundo forjada por uma época definida tem a mesma estrutura do que o mundo imediatamente entenda ser apropriado como uma forma de organização política. Para Schmitt, todos os conceitos significativos da teoria moderna do Estado são conceitos teológicos secularizados (SCHMITT, 2006, p. 35), não só por causa de seu desenvolvimento histórico - em que foram transferidos da teologia para a teoria do Estado - mas

${ }^{8}$ No original: l'effet de l'interprétation authentique est qu'elle s'impose, quel que soit son contenu. Le texte interprété n'a pas et ne peut avoir d'autre sens que celui que lui a donné l'autorité habilitée. 
também por causa de sua estrutura sistemática, cujo reconhecimento é necessário para uma consideração sociológica desses conceitos.

A analogia entre a mais pura forma de exercício do poder político no Estado (a decisão do soberano no caso excepcional), com o que a teologia concebe como milagre também é considerada um fato estrutural da sociedade ocidental atual.

Muitos devem estar cientes do estilo de escrita muito peculiar de Schmitt, que é, de modo geral, claro, peremptório e elusivo. Na verdade, Schmitt não se importa em examinar o que é ou deveria ser um milagre. Ele apenas o pressupõe e deixa a analogia com um poderoso e provocador insight. $\mathrm{O}$ que ele persegue são os fatos básicos e elementares de poder, política, lei e Estado, alguns dos quais podem ser tão óbvios e simples que se tornam difíceis de ver. E ele repete frequentemente que não pretende ser metafórico em tais descrições, como no antagonismo "amigo e inimigo", alçado à condição de critério de identificação do político, Diríamos que ele deseja apresentar esses fatos básicos em sua "nudez".

Assim, e agora partindo da metodologia cautelosa baseada em fatos de Schmitt, desejamos empregar uma metáfora para estruturar nosso argumento sobre os limites das considerações de Schmitt sobre as questões centrais dos fenômenos jurídicos/políticos.

Primeiro, no entanto, sentimos que é necessário gastar algumas palavras sobre o que aqui será entendido como milagre. Um milagre é o que as pessoas acreditam ser um milagre. Em última análise, não pode ser provado. Um milagre nesse sentido "existiria" mesmo que não existam poderes sobrenaturais. É desse ponto de vista cético, literalmente, apenas uma questão de crença; de atividade social criadora de significados, que aqui desejamos observar de fora, como a ciência da religião observaria as várias religiões próprias.

Podemos, então, acrescentar que se vê um milagre onde algum tipo de evento inesperado é atribuído a uma intervenção deliberada de Deus. No catolicismo, principalmente na maioria das vezes devido aos apelos dirigidos a Deus por santos ou anjos.

Achamos que é possível descrever as circunstâncias em que os milagres são pensados para acontecer como rupturas do que a comunidade acreditava ser o curso "natural" dos acontecimentos e o próprio milagre como uma explicação "sobrenatural" que recompõe essa ruptura, tornando-se novamente palatável para uma compreensão das pessoas do por que as coisas aconteceram da maneira que aconteceram e não como era inicialmente esperado.

Agora, temos a sensação de que, embora essa definição de milagre que estamos usando não pareça totalmente incompatível com a que Schmitt daria, devemos reconhecer que não é a mesma. O que Schmitt parece querer dizer é que lá onde a 
"vontade de Deus" repousa no milagre teológico, será colocada a "vontade do soberano" no exercício do poder para decidir em caso de exceção. Nesse sentido, o que dizemos aqui não é realmente rebatendo Schmitt, mas acrescentando a sua visão, ainda que de forma crítica.

A crítica aqui se baseia no fato de que parece que na explicação de Schmitt falta o ponto principal sobre a "magia" da lei. Pensamos que ele está certo, no entanto, se alguém considera apenas a magia da "política", a qual ele reduz a própria lei (Cf. KERVÉGAN, 2006, p. 9).

A metáfora que desejamos apresentar pretende ter a recomposta explicação dada pela ideia de um milagre em comparação com as "roupas", com as quais "veste" o fato "rompedor" (o "fato nu", que Schmitt procura desvendar) para que, então, seja visto de forma diferente e mais conveniente. Portanto, se conseguíssemos considerar a "exceção" como "milagre", seria porque existe a possibilidade de absorver e explicar essa anormalidade convenientemente. Neste caso, é o poder absoluto do soberano (poder de Deus), e a crença na necessidade universal de obedecer a um soberano (obedecer a Deus), que permite uma explicação conveniente da ruptura.

A questão central aqui é: "nudez" é realmente relevante para a explicação do que são "roupas". Mas se alguém quiser saber mais sobre como os seres humanos experimentam roupas, o que significa para eles, o que é, por exemplo, a moda, então a nudez é muito grosseira como um contraste. Em outras palavras, não se pode distinguir a linguagem própria da moda partindo do simples fato de que a roupa esconde o corpo nu. Então, a nudez explica o que as roupas são, mas não o que as roupas significam.

No caso, por exemplo, da equidade, existe uma ruptura de uma regra. Às vezes, realiza-se exatamente o oposto do que a regra afirma. E, milagrosamente, através do argumento da equidade, pode-se acreditar que a regra não foi irrompida e que seu "espírito" escondido é ao final confirmado pela desobediência à "letra" do texto. Uma vez que este "espírito" não pode ser diretamente experimentado, isso também acaba por ser, literalmente, uma questão de crença e, o mais importante, uma questão de persuasão.

O sucesso de tal persuasivo empreendimento deixa claro, acreditamos, a questão central da cultura jurídica romanística e do common law, que concebem o direito como conhecimento tecnológico. Somente a partir dessa base, essas culturas tornam possível que tão re-composição das expectativas por meio da equidade tenham lugar. Isso torna possível acreditar que os juízes (ou qualquer pessoa que decida de acordo com a "ciência jurídica") fazem isso em vez daquilo, porque sabem de algo (têm o conhecimento de algo) e não porque desejam algo.

O postulado de Schmitt de que uma decisão sobre se algo é ou não é político já é uma decisão política e torna a política onipresente, o que é algo teológico em si, 
embora nós também acreditemos que é inegável. O que está faltando, no entanto, achamos nós, em Schmitt, são as contingências da própria ideia de ciência jurídica, não qual nós acreditamos, mas que vemos como um elemento inevitável do que os juristas acreditam quando fazem o que fazem.

Schmitt, como nós, considerava a neutralidade como uma ilusão. A ciência jurídica, como tem sido pensada pelos juristas desde os romanos, é a principal ferramenta para a neutralidade. Assim, o estudo da cultura jurídica deve ter em conta a crença de que o que os juristas fazem deriva de uma forma de conhecimento, não de um poder absoluto. É uma retórica e, se por um lado, podemos dizer que não é verdade, por outro lado, essa negação não deve prejudicar a percepção de como ela funciona na sociedade. Para concluir em termos de analogia: posso ser cientista da religião mesmo que não acredite em entidades divinas.

\section{CONCLUSÃO}

Roy Wagner, em seu Símbolos que representam a si mesmos, conta a história de Berengário, escolástico de Tours e arquidiácono de Angers, o pupilo mais brilhante de Fulberto de Chartres, estudante de gramática e retórica e um dotado versificador em latim do século XI, o qual, hábil em dialética, ficou conhecido sobretudo pela afirmação e teimosa defesa da natureza figurativa da eucaristia.

Segundo Wagner, Berengário preocupava-se com a mediação de dualidades básicas e, mais especificamente, com a transformação do sangue e da substância. Para o professor de antropologia da Universidade de Virgínia, a eucaristia de Berengário seria o tropo (a metáfora, a coordenada referencial) de uma mediação da relação hierárquica entre Deus e o homem (WAGNER, 2017, p. 128).

O antropólogo assevera que a noção de comida sacramental ou de compartilhamento de substância como ligação mediadora do humano com o divino tem suas raízes na antiga tradição judaico-cristã, associada a duas pressuposições: a de que a comida que Deus oferece é Sua palavra, incorpora Sua sabedoria, e a de que comer a sabedoria de Deus estabelece um acordo vinculativo, "um pacto, entre comensais, de obedecer às suas palavras" (WAGNER, 2017, p. 128 apud FEELEYHARNICK, 1981).

Para Berengário, e para os cristãos que o precederam e o seguiram, "comer a sabedoria de Deus" dessa forma implicava, de uma maneira ou de outra, uma presença divina identificável com Jesus Cristo como mediador (sacrificial) entre Deus e homem e, por extensão, com a Igreja que representa Cristo por meio de seu direito de sucessão à Sé de Pedro, de forma que uma figura triangular com Deus assumindo a aresta superior e o homem e a eucaristia ocupando, cada um, as arestas restantes - 
$\overline{\text { de base - representa a formulação mediadora básica da cristandade latina medieval. }}$ Wagner vai mais além com a análise dessa figuração, mas basta-nos ficar por aqui.

Berengário estava destinado a ser o maior dissidente de sua era. Após a reforma papal de Gregório VII, contudo, é provável, seguindo uma reflexão do próprio Roy Wagner, que uma Igreja militante que quisesse fazer valer o direito de nomear seus próprios funcionários também precisasse de um sacramento não derivativo.

A época de Gregório VII e o despertar da reforma papal estavam comprometidos com a realidade da transformação eucarística; ela buscava um milagre onde a era anterior havia encontrado um mistério, tendo sido Berengário forçado a se retratar em 1059 (accidentia transformada em substantia).

A literalização ou aceitação do sacramento figurativo agostiniano (sacramento agostiniano este defendido por Berengário) do período carolíngio como realidade, representando uma substituição de uma sequência de pensamento medieval, coincide com a controvérsia de investidura e com a afirmação do direito da Santa Sé de investir seus próprios funcionários, em contraposição à sua nomeação claramente política feita por lordes seculares, prática comum desde antes de Carlos Magno (WAGNER, 2017, p. 135).

Metaforicamente, consideremos, para os efeitos do que se quer aqui demonstrar, que a substanciação (literalização) do simbólico (figurativo) (re)estruturada, politicamente, sob o discurso do milagre pode ser equiparada à substanciação do espírito da lei na literalidade da letra, com isso se querendo alcançar formas a priori sedimentadas numa permanência do teológico (cosmogonia) no metodológico do direito.

Nesse sentido, a decisão jurídica funcionaria como catalisador das formas jurídicas, uma espécie de copula mundi, sendo capaz de retomar retoricamente vezes a fio a literalidade como veste encobridora do arbítrio e os juristas uns mentirosos que descrevem uma norma que não há, estrutura e estruturante de uma ordem que também não há, mas que se admite como verdadeira operacionalmente através dos símbolos, comparados por Wagner a uma "moeda", unidade monetária acadêmica, capaz de comprar a produção semântica dos "objetos" de pesquisa (WAGNER, 2017, p. 2), aparentemente na tentativa de frear a inflação causada pelas novas cunhagens, denominações reavaliadas e reemitidas dos sentidos possíveis.

As moedas, na Bíblia, foram usadas para trair o Verbo.

\section{REFERÊNCIAS}

BENJAMIN, Walter. Magia e técnica, arte e política: Ensaios sobre literatura e história da cultura. São Paulo: Editora Brasiliense, 1987. 
BOURDIEU, Pierre. O poder simbólico. Rio de Janeiro: Editora Bertrand Brasil, 1989.

CASTRO JR., Torquato. Metáforas de letras em culturas jurídicas da escrita: como se é fiel à vontade da lei? In: BRANDÃO, Cláudio; CAVALCANTI, Francisco; ADEODATO, João Maurício (Coords.). Princípio da legalidade: da dogmática jurídica à teoria do direito. Rio de Janeiro: Forense, 2009.

FERRAZ JR., Tercio Sampaio. Direito, retórica e comunicação: subsídios para uma pragmática do discurso jurídico. São Paulo: Atlas, 2015.

JUST, Gustavo; ASSIS, Igor Beltrão Castro de. A teoria dos constrangimentos jurídicos e seu teste de verdade: uma análise retroditiva da arguição de descumprimento de preceito fundamental $\mathrm{n}^{\mathrm{o}}$ 132/RJ. Caderno de relações internacionais, Recife, no 8, p. 159-206, jan./jun, 2014.

KELSEN, Hans. Teoria pura do direito. Coimbra: Arménio Amado, 1984.

KERVÉGAN, Jean-François. Hegel, Carl Schmitt: o político entre a especulação e a positividade. Barueri: Manole, 2006.

LAZARUS, Sylvain. Antropologia do nome. São Paulo: Editora Unesp, 2017.

PLATÃO. A república. São Paulo: Martin Claret, 2008.

RODRIGUEZ, José Rodrigo. Controlar a profusão de sentidos: a hermenêutica jurídica como negação do subjetivo. In: BOUCAULT, Carlos Eduardo de Abreu; RODRIGUEZ, José Rodrigo (Coords.). Hermenêutica plural: possibilidades jusfilosóficas em contextos imperfeitos. São Paulo: Martins Fontes, 2002.

SALDANHA, Nelson. Da teologia à metodologia: secularização e crise do pensamento jurídico. Belo Horizonte: Del Rey, 2005.

SALDANHA, Nelson. Teoria do direito e crítica histórica. Rio de Janeiro: Livraria Freitas Bastos, 1987. 
IGOR CASTRO BELTRÃO

TORQUATO JUNIOR CASTRO

SCHMITT, Carl. Teologia política. Belo Horizonte: Del Rey, 2006.

TROPER, Michel. La théorie du droit, le droit, l'état. Paris: Presses Universitaires de France, 2001.

WAGNER, Roy. Símbolos que representam a si mesmos. São Paulo: Editora Unesp, 2017.

WARAT, Luis Alberto. O direito e sua linguagem. Porto Alegre: Sergio Antonio Fabris Editor, 1984.

WARAT, Luis Alberto. Introdução geral ao direito - Interpretação da lei: temas para uma reformulação. Porto Alegre: Sergio Antonio Fabris Editor, 1994. 